Vera Trost:

\title{
Abordnung an die Vertretung des Landes Baden- Württemberg bei der Europäischen Union
}

Von Februar bis Juli 2004 war ich an die Vertretung des Landes BadenWürttemberg bei der Europäischen Union in Brüssel abgeordnet.

\section{Die Vertretung des Landes Baden-Württemberg bei der Europäischen Union}

Das Land Baden-Württemberg hat als eines der ersten deutschen Länder 1987 ein Informationsbüro in Brüssel eingerichtet. Mit der zunehmenden Bedeutung europäischer Entscheidungen auf allen Ebenen wurde das Informationsbüro 1990 personell ausgebaut und 2001 in „Vertretung des Landes BadenWürttemberg bei der Europäischen Union" umbenannt. 2002 erwarb das Land Baden-Württemberg für die Landesvertretung ein eigenes Gebäude in der Rue Belliard 60 - 62 und eröffnete es am 5. Februar 2004 feierlich.

\section{Aufgaben der Landesvertre- tung}

Die Vertretung des Landes BadenWürttemberg bei der Europäischen Union unterhält enge Kontakte zur Europäischen Kommission, dem EUMinisterrat, dem Europäischen Parlament, der Ständigen Vertretung der Bundesrepublik Deutschland und anderen ansässigen Organisationen.
Sie repräsentiert in Brüssel das Land und nimmt die Interessen BadenWürttembergs bei der Europäischen Union wahr.

\section{Das neue Gebäude}

Mit der Eröffnung des neuen Gebäudes hat die Landesregierung BadenWürttembergs einen wichtigen Schritt zur Stärkung der Präsenz des Landes in Brüssel vollzogen und die Voraussetzungen dafür geschaffen, dass BadenWürttemberg auch in einer erweiterten Europäischen Union als aktiver Partner zur Schaffung eines Europas der Regionen vor Ort in Brüssel sichtbar ist.

Das neue Gebäude der Landesvertretung befindet sich inmitten des EUViertels nur wenige Gehminuten entfernt vom Europäischen Parlament, dem Ausschuss der Regionen, der EUKommission und dem EU-Ministerrat an der Rue Belliard, einer der Hauptachsen, die durch das EU-Viertel führen, in direkter Nachbarschaft zum Brüsseler Goethe-Institut. Im Umkreis befinden sich wichtige Botschaften, EU-Vertretungen befreundeter Regionen sowie anderer Interessenvertreter auf europäischer Ebene, das Büro des Beobachters der deutschen Länder sowie die deutsche Ständige Vertretung bei der EU. 